\title{
An Experiment With an Employment Sector Question
}

Ariel A Finno*, Jessica Kohout ${ }^{\dagger}$

Tags: survey practice

DOI: $10.29115 /$ SP-2010-0018

\section{Survey Practice}

Vol. 3, Issue 4, 2010

An Experiment With an Employment Sector Question

The APA Salaries in Psychology Survey is conducted on a bi-ennial basis by the American Psychological Association, a non-profit member association. The purpose of the survey is to collect current salary information at the masters and doctoral levels for all APA members. Meta-data on which this article is based were collected in June of 2009. For the 2009 effort an item on current employment setting was presented to respondents using two different formats (open text vs. forced choice drop down). Members of the sample were randomly assigned to one of two groups (Branch A or Branch $\mathrm{B}$ ) for the on-line survey. Results showed that participants who received the open text question format were significantly more likely to provide employment setting data compared to participants who received the forced choice drop-down format, and participants who received the open text question format were significantly more likely to provide usable data compared to participants who received the forced choice drop-down format.

\section{BACKGROUND}

The APA Salaries in Psychology data are overwhelmingly doctoral level, and this reflects the prevailing situation among APA members. As is the case with any member association, the APA is interested in using technology to ease the survey response burden on its members in order capture more robust data. For many years APA has struggled with accurately and consistently describing the members' employment settings and positions. For all past efforts the item requesting data on members current employment setting has been offered as an open text box with a numbered list of popular employment settings for master's or doctoral-level individuals in psychology. As individuals with a doctorate degree in psychology have expanded their employment setting choices the employment setting list has lengthened, requiring more space on both paper and online instruments. Past attempts to utilize space more efficiently in online instruments through the use of a 'pop-up box' containing

\footnotetext{
* Institution: American Psychological Association

† Institution: American Psychological Association
} 
the employment settings that participants could click on resulted in technical issues and respondents abandoned the survey in frustration.

Since past efforts have only provided the employment setting question in the form of an open text box with a numbered list of employment setting options, a certain percentage of respondents provided incomplete data that could not be analyzed or they skipped the question entirely. Unusable or incomplete data account for as little as 2 percent (2007 APA Salaries in Psychology Survey) to as much as 20 percent (2005 APA Salaries in Psychology Survey) of the employment item analysis for previous efforts. Other survey efforts from APA experience similar broad ranges of missing and unusable data for the employment setting item depending upon survey effort and year.

\section{METHODS}

To that end an experiment testing different question formats was implemented in the 2009 APA Salaries in Psychology Survey effort for the item on current employment setting. Members of the sample for the online instrument were randomly assigned to one of two groups. Each group was presented with the identical question using different formats, either an open text box, which had been used in prior surveys with varying degrees of success, or a drop-down forced choice design. This would be the first attempt at testing the effectiveness of different question formats for the employment setting item for item response rate and data quality.

Individuals who requested a paper version of the instrument $(N=10)$ were not included in this investigation, rather, only data for those individuals who responded to the online survey $(N=12,825)$ were used.

Data collection began in June of 2009 with an approximate sample of 47,239 members receiving the survey. The true overall response rate for this effort was approximately 27 percent. Data indicate that 2009 respondents and those in the sample were quite similar with respect to key variables of interest. Differences, where they existed, were not substantive.

Groups were created using a branching feature within the online survey tool that randomly assigned 50 percent of respondents to the question formatted as an open text box (Branch $A$ ), and 50 percent to the forced choice drop-down box format (Branch $B$ ). Appendix $A$ is a visual representation of the two different question formats for Branch $\mathrm{A}$ and for Branch $\mathrm{B}$.

Respondents in the two groups did not differ substantively in their demographics (mean year degree was earned, disability status, gender, race/ ethnicity, etc.) from each other. Table 1 and Table 2 compare the demographic characteristics of respondents to Branch A and respondents to Branch B. 
Table 1 Characteristics of APA members by question item format, 2009.

\begin{tabular}{|c|c|c|c|c|c|c|c|}
\hline & & \multicolumn{2}{|c|}{ Branch A } & \multicolumn{2}{|c|}{ Branch B } & \multicolumn{2}{|l|}{ Total } \\
\hline & & $\mathrm{N}$ & $\%$ & $\mathrm{~N}$ & $\%$ & $\mathrm{~N}$ & $\%$ \\
\hline$N=$ & & 6,374 & 49.7 & 6,441 & 50.3 & 12,815 & 100.0 \\
\hline \multirow[t]{3}{*}{ Gender } & Female & 3,603 & 56.5 & 3,584 & 55.6 & 7,187 & 56.0 \\
\hline & Male & 2,771 & 43.5 & 2,856 & 44.3 & 5,627 & 43.9 \\
\hline & Not specified & 0 & 0.0 & 1 & 0.0 & 1 & 0.0 \\
\hline \multirow[t]{9}{*}{ Race/ethnicity } & African American/Black & 211 & 3.3 & 197 & 3.1 & 408 & 3.2 \\
\hline & $\begin{array}{l}\text { American Indian or Alaskan } \\
\text { Native }\end{array}$ & 20 & 0.3 & 19 & 0.3 & 39 & 0.3 \\
\hline & Asian & 145 & 2.3 & 176 & 2.7 & 321 & 2.5 \\
\hline & Caucasian/White & 5370 & 84.2 & 5,384 & 83.6 & 10,754 & 83.9 \\
\hline & Hispanic & 197 & 3.1 & 212 & 3.3 & 409 & 3.2 \\
\hline & $\begin{array}{l}\text { Native Hawaiian or Pacific } \\
\text { Islander }\end{array}$ & 12 & 0.2 & 8 & 0.1 & 20 & 0.2 \\
\hline & Other & 0 & 0.0 & 0 & 0.0 & 0 & 0.0 \\
\hline & $\begin{array}{l}\text { Multiple racial/ ethnic } \\
\text { background }\end{array}$ & 103 & 1.6 & 104 & 1.6 & 207 & 1.6 \\
\hline & Not specified & 316 & 5.0 & 341 & 5.3 & 657 & 5.1 \\
\hline \multirow[t]{3}{*}{ Disability } & No & 5,912 & 92.8 & 5,976 & 92.8 & 11,888 & 92.8 \\
\hline & Yes & 186 & 2.9 & 182 & 2.8 & 368 & 2.9 \\
\hline & Not specified & 276 & 4.3 & 283 & 4.4 & 559 & 4.4 \\
\hline \multirow{4}{*}{$\begin{array}{l}\text { Highest Degree } \\
\text { Earned }\end{array}$} & Doctorate & 6,135 & 96.3 & 6,210 & 96.4 & 12,345 & 96.3 \\
\hline & Master's & 231 & 3.6 & 227 & 3.5 & 458 & 3.6 \\
\hline & Other Degree & 5 & 0.1 & 4 & 0.1 & 9 & 0.1 \\
\hline & Not Specified & 3 & 0.0 & 0 & 0.0 & 3 & 0.0 \\
\hline \multirow[t]{2}{*}{ Licensure Status } & $\begin{array}{l}\text { Currently Licensed and/or } \\
\text { certified }\end{array}$ & 3,913 & 61.4 & 3,910 & 60.7 & 7,823 & 61.0 \\
\hline & $\begin{array}{l}\text { Not currenlty licensed and/or } \\
\text { certified }\end{array}$ & 2,460 & 38.6 & 2,531 & 39.3 & 4,991 & 38.9 \\
\hline \multirow{3}{*}{$\begin{array}{l}\text { Psychology Major } \\
\text { Field }\end{array}$} & DHS & 3,459 & 54.3 & 3,492 & 54.3 & 6,951 & 54.2 \\
\hline & Research/Other & 2,915 & 45.7 & 2,949 & 45.7 & 5,864 & 45.8 \\
\hline & Not Specified & 0 & 0.0 & 0 & 0.0 & 0 & 0.0 \\
\hline \multirow{2}{*}{$\begin{array}{l}\text { Early Career } \\
\text { Doctorate }\end{array}$} & No & 4,804 & 75.4 & 4,889 & 75.9 & 9,693 & 75.6 \\
\hline & Yes & 1,570 & 24.6 & 1,552 & 24.1 & 3,122 & 24.4 \\
\hline
\end{tabular}

Source: APA Salary Survey, 2009. Compiled by APA Center for Workforce Studies, June 2010. 
Table 2 Statistics of APA members by question item format, 2009.

$\begin{array}{lll}\text { Year Degree Earned } & \text { Branch A } & \text { Branch B } \\ \text { N } & 5,722 & 5,788 \\ \text { Mean } & 1991 & 1990 \\ \text { Median } & 1992 & 1992 \\ \text { Mode } & 2006 & 2005 \\ \text { Std. Deviation } & 11.129 & 11.186 \\ \text { Not Specified } & 67 & 79 \\ \text { Hours per week in primary position } & & \\ \text { N } & 5,592 & 5,652 \\ \text { Mean } & 41.06 & 41.15 \\ \text { Median } & 40 & 40 \\ \text { Mode } & 40 & 40 \\ \text { Std. Deviation } & 11.554 & 11.457 \\ \text { Not Specified } & 197 & 215 \\ \text { Total years work experience } & & \\ \text { N } & 5,530 & 5,605 \\ \text { Mean } & 18.22 & 18.44 \\ \text { Median } & 18 & 18 \\ \text { Mode } & 25 & 30 \\ \text { Std. Deviation } & 11.225 & 11.251 \\ \text { Not Specified } & 259 & 262\end{array}$

Source: APA Salary Survey, 2009. Compiled by APA Center for Workforce Studies, June 2010.

This experiment focused on the following:

1. Comparison of item response rates utilizing an open-ended text item (Branch A) versus a series of drop-down forced choice items (Branch B), and,

2. Comparison of amount of usable data received from respondents through an open-ended text item (Branch A) versus a series of dropdown forced choice items (Branch B).

These questions were addressed using univariate and bivariate descriptive statistics (e.g., percentages and cross-tabulations with chi-square).

\section{FINDINGS/RESULTS}

Of the 12,825 survey participants, 6,374 (49.7 percent) received the open text box question format (Branch $A$ ) and 6,441 (50.3 percent) received the series of drop-down forced choice question format (Question B).

\section{RESPONSE RATE WAS HIGHER FOR BRANCH A PARTICIPANTS}

The response rate for the employment setting question differed dramatically based on the format of the item: open text box, or forced choice drop down menu.

Figure 1 presents response rates for both experimental groups. While 
approximately 97 percent of persons who received the open text box format (Branch A) provided some sort of response, 86 percent of individuals who received the forced choice drop-down format provided a response. Put another way, individuals who received Branch B were almost 5 times more likely to not respond to the employment setting item than individuals who received Branch A.

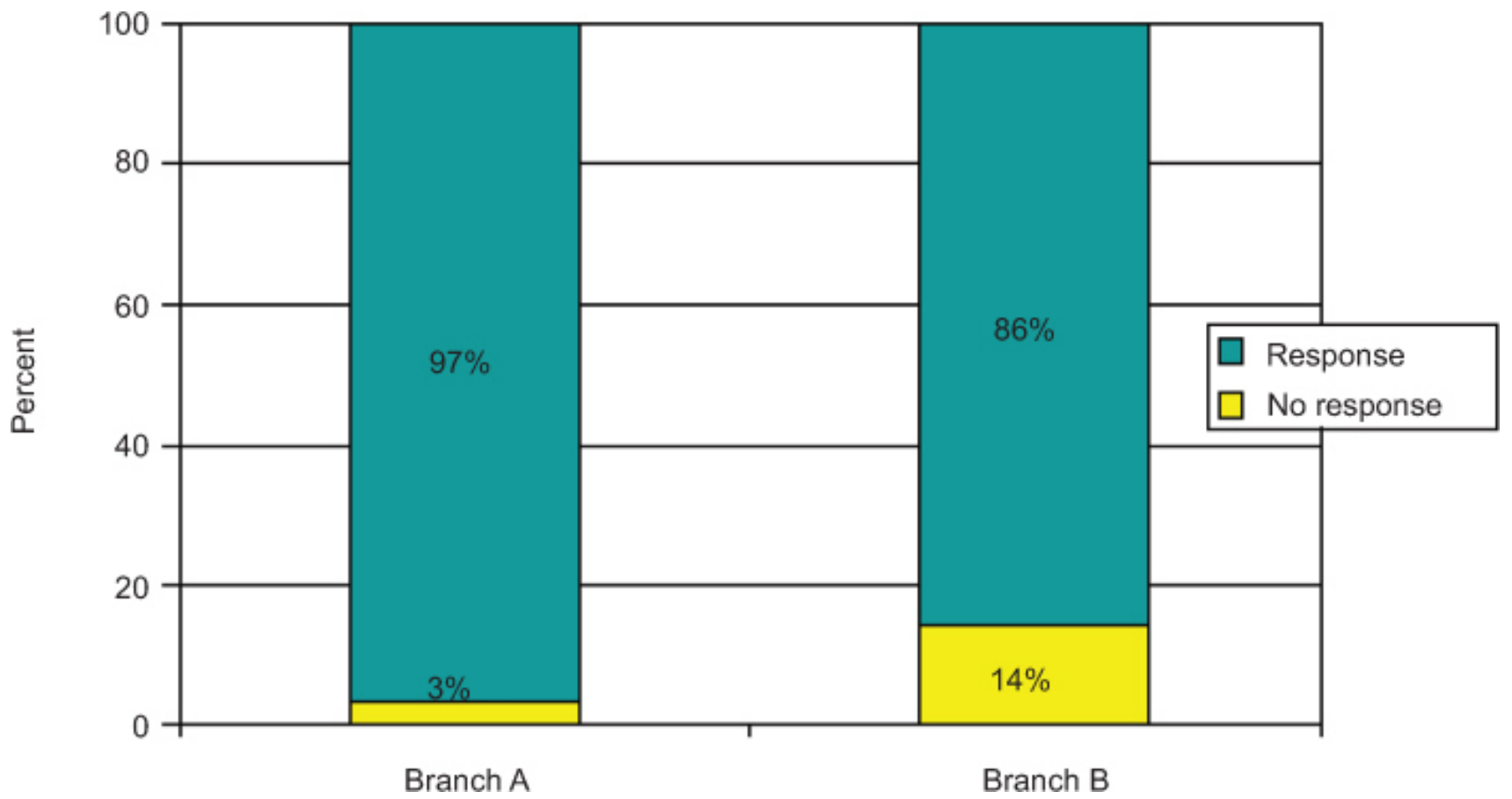

Figure 1 Response rates for Question Item Branches A and B.

Participants who were randomly assigned to Branch A (open text format) were significantly more likely to provide data than were those who were assigned to Branch B (series of forced choice drop-down items) $\left(\chi^{2}=459.723, \mathrm{df}=1\right.$, $p<0.001)$.

\section{INCOMPATIBLE DATA MORE LIKELY FOR BRANCH B PARTICIPANTS}

Additionally, approximately 1 percent of those who received Branch $B$ and who responded, provided a response that was not fit for analysis. Data that could not be reconciled or verified through other sources of information were removed from analysis.

Participants who were randomly assigned to Branch A (open text question item format) were significantly more likely to provide usable employment setting data, than were those who were assigned to Branch B (series of forced choice drop-down items $)\left(\chi^{2}=58.461, \mathrm{df}=1, p<0.001\right)$.

\section{DISCUSSION}

Our results indicated that in comparison with a forced choice drop-down question format, the open text box with list of employment settings format 
seemed to promote not only a better response for that item, but collected higher quality data on employment setting as well. Based on the results it was determined that the open text box question format should continue to be the format used in APA surveys that inquire about members current employment settings. Preliminary data from three other survey efforts currently in the field that utilize the open text format for the employment setting item reveal that there continues to be variability in the response rate for this question (from one to four percent item nonresponse dependant upon the particular survey effort) (2009 APA Doctorate Employment Survey 2010 APA Employment Update), although it is much lower than the item nonresponse for the forced choice drop-down format.

In theory the use of multiple forced choice drop down questions might be thought to yield 'cleaner' data since respondents are limited to choosing an employment setting from only four or five increasingly narrow options at a time, it seems that not allowing respondents to view the complete list of employment settings (currently 72 settings) may increase frustration by not being able to immediately see one's employment setting, leading to abandonment of the question item all together.

It should be noted that despite the open text box format being a better choice in terms of yielding the most robust data, there were still disadvantages that must be addressed. These include the high variability in item nonresponse by survey effort, and the ever increasing number of employment setting codes, forcing the allocation of more space to the list in both online and paper surveys.

Based on the results of this survey format experiment some of our recommendations for survey researchers are as follows:

1. Thorough review of the characteristics of your survey population prior to instrument creation. This may provide insight into which question item format will yield the most accurate survey results.

2. While not always possible, keeping abreast of the characteristics of your survey population will also assist in the creation of employment setting lists that are as concise and accurate as possible, ensuring it takes up the least amount of space in your survey (whether it be online or paper format) as absolutely necessary, saving you money and the respondent time.

3. Finally, careful examination of all survey item formats should be conducted with every new iteration, no matter how long a particular method has been in use. With the constant emergence of new research and technologies, question item formats that may have worked well in past survey efforts can be quickly supplanted with something even better. However, before altering formats careful consideration should be made to ensure that new methods of asking items will not adversely affect any longitudinal work being 
conducted.

\section{CONCLUSION}

We conclude that until a better alternative for collecting usable data on employment setting can be found, it is better to use the open text box with a displayed accompanying setting list than to potentially lose more data through item nonresponse, or collect data that is determined to be unusable and must be removed from analysis, through the use of a forced choice drop-down format. More research is needed to evaluate alternatives for displaying the employment setting question item to respondents, while both maintaining and increasing data quantity and quality.

\section{APPENDIX A}

Employment Settings Branches A \& B (participant's viewed either one question item format or the other)

\section{BRANCH A}

Employment Setting. Please indicate your PRIMARY employment setting as a two digit code. Please scroll down to see a complete list of employment setting codes. (PRIMARY SETvTING IS THE ONE IN WHICH YOU SPEND THE MOST TIME)

\section{UNIVERSITY (NOT MEDICAL OR INDEPENDENT PROFESSIONAL SCHOOL) SETTINGS}

01 Psychology department

02 Education department

03 Business school or department

04 Other academic department or unit

05 Management or administrative office

06 Student counseling or services center

07 Research center or institute

24 Professional school of psychology, University based

09 Other university setting

\section{FOUR-YEAR COLLEGE SETTINGS}

11 Psychology department

12 Education department

13 Business school or department

14 Other academic department or unit

15 Management or administrative office

16 Student counseling or services center

17 Research center or institute

19 Other four-year college setting

\section{OTHER EDUCATIONAL SETTINGS}

21 Two-year college 
22 Medical school, psychiatry department

23 Medical school, other than psychiatry department

28 Independent professional school of psychology

29 Professional schools not listed above (e.g., law, nursing)

25 Elementary or secondary school

26 School system district office

27 Other educational setting (e.g., vocational or special education)

PRIVATE PRACTICE SETTINGS

$\mathbf{4 1}$ Individual private practice

42 Group psychological practice

43 Primary care group practice

ORGANIZED HUMAN SERVICE SETTINGS

31 Public general hospital

32 Private general hospital

33 City/county/state psychiatric hospital

34 Not for profit, private psychiatric hospital

36 For profit, private psychiatric hospital

35 VA medical center

37 Military hospital (e.g., Air Force)

71 Rehabilitation facility

47 Counseling or guidance center (not university or college)

44 Outpatient mental health clinic, free-standing

45 Community mental health center or clinic (CMHC)

73 Primary care office/community health center

40 Nursing home

48 Specialized health service (e.g., substance abuse or mental retardation)

39 Preferred Provider Organization (PPO)

38 Independent Practice Association (IPA)

46 Health Maintenance Organization (HMO), excluding IPA

70 Other managed care setting

49 Other human service setting not listed above

BUSINESS, GOVERNMENT AND OTHER EMPLOYMENT SETTINGS

51 Self-employed (not private practice)

52 Consulting firm

53 Private research organization or lab

54 Govt. research organization or lab

56 Independent consultant

72 Union

55 Business or industry (excluding consulting firm or research organization)

61 Criminal justice system

62 Military service (not military hospital)

63 Federal government agency (other than above settings)

64 State government agency (other than above settings) 
61 Local government agency (other than above settings)

62 Other non-profit organization

69 Other non-educational or non service setting not listed above

\section{BRANCH B}

Employment Setting. Please indicate the ONE employment category and corresponding setting that best describes your PRIMARY employment. (PRIMARY SETTING IS THE ONE IN WHICH YOU SPEND THE MOST TIME)

PLEASE SELECT A GENERAL EMPLOYMENT CATEGORY FROM THE LIST BELOW. YOU WILL BE ABLE TO REFINE THIS SELECTION.

-Please Select-

Educational: University (not medical or professional school)

Educational: Four-Year College

Educational: Other Educational Setting

Private Practice Setting

Organized Human Services

Business, Government, and Other Employment Setting

(REFINING OPTION FOR UNIVERSITY) PLEASE SELECT A UNIVERSITY EMPLOYMENT SETTING FROM THE LIST BELOW.

-Please Select-

01 Psychology department

02 Education department

03 Business school or department

04 Other academic department or unit

05 Management or administrative office

06 Student counseling or services center

07 Research center or institute

24 Professional school of psychology, University based

09 Other university setting

Please specify other University employment setting:

(REFINING OPTION FOR FOUR YEAR COLLEGE) PLEASE SELECT A FOUR-YEAR COLLEGE EMPLOYMENT SETTING FROM THE LIST BELOW.

-Please Select-

11 Psychology department

12 Education department

13 Business school or department

14 Other academic department or unit

15 Management or administrative office

16 Student counseling or services centeresearch center or institute

19 Other four-year college setting

Please specify other Four-Year College employment setting: 
(REFINING OPTION FOR OTHER EDUCATIONAL) PLEASE SELECT AN OTHER EDUCATIONAL EMPLOYMENT SETTING FROM THE LIST BELOW.

-Please Select-

21 Two-year college

22 Medical school, psychiatry department

23 Medical school, other than psychiatry department

28 Independent professional school of psychology

29 Professional schools not listed above (e.g., law, nursing)

25 Elementary or secondary school

26 School system district office

27 Other educational setting (e.g., vocational or special education)

Please specify Other Educational employment setting:

(REFINING OPTION FOR PRIVATE PRACTICE) PLEASE SELECT A PRIVATE PRACTICE EMPLOYMENT SETTING FROM THE LIST BELOW.

-Please Select-

41 Individual private practice

42 Group psychological practice

43 Primary care group practice

(REFINING OPTION FOR ORGANIZED HUMAN SERVICE) PLEASE SELECT AN ORGANIZED HUMAN SERVICE SETTING FROM THE LIST BELOW.

-Please Select-

31 Public general hospital

32 Private general hospital

33 City/county/state psychiatric hospital

34 Not for profit, private psychiatric hospital

36 For profit, private psychiatric hospital

35 VA medical center

37 Military hospital (e.g., Air Force)

71 Rehabilitation facility

47 Counseling or guidance center (not university or college)

44 Outpatient mental health clinic, free-standing

45 Community mental health center or clinic (CMHC)

73 Primary care office/community health center

$\mathbf{4 0}$ Nursing home

48 Specialized health service (e.g., substance abuse or mental retardation)

39 Preferred Provider Organization (PPO)

38 Independent Practice Association (IPA)

46 Health Maintenance Organization (HMO), excluding IPA

70 Other managed care setting

49 Other human service setting not listed above

Please specify other Organized Human Service employment setting: 
(REFINING OPTION FOR BUSINESS, GOVERNMENT OR OTHER) PLEASE SELECT A BUSINESS, GOVERNMENT, OR OTHER EMPLOYMENT SETTING FROM THE LIST BELOW.

-Please Select-

$\mathbf{5 1}$ Self-employed (not private practice)

52 Consulting firm

53 Private research organization or lab

54 Govt. research organization or lab

56 Independent consultant

72 Union

55 Business or industry (excluding consulting firm or research organization)

61 Criminal justice system

62 Military service (not military hospital)

63 Federal government agency (other than above settings)

64 State government agency (other than above settings)

65 Local government agency (other than above settings)

66 Other non-profit organization

69 Other non-educational or non service setting not listed above

Please specify other Business, Government, or Other employment setting: 


\section{REFERENCES}

“2005 APA Salary Survey Data (Unpublished Analysis).” 2005. Washington, DC: American Psychological Association.

Finno, A.A., D. Michalski, B. Hart, J.L. Kohout, and M. Wicherski. 2010. "Report of the 2009 APA Salary Survey.” Washington, DC: American Psychological Association.

Wicherski, M. 2010. "Report of the 2007 APA Salary Survey: Revised.” Washington, DC: American Psychological Association. 